\title{
Chronic Subdural Hematoma A Prospective Study
}

\author{
Ali K. AL-Shalchy* \\ Wameedh Q. Abdul-hussein** \\ Saif S. AL-Musawy**
}

\author{
FICMS, MRCS, FRCS \\ FICMS, CABNS \\ FICMS
}

\begin{abstract}
:
Fac Med Baghdad 2018; Vol.60, No.1 Received: Feb. 2018 Accepted: Mar. 2018
\end{abstract}

Background: Chronic subdural hematoma is a blood collection in the subdural space for more than 3 weeks from the onset of the bleeding. It is more likely to develop in infancy and after the age of 60 years. The incidence of subdural hematoma is 1- 2 per 100,000 people per year.

Objective: To delineate the most common feature aspects of SDH like: age, predisposing factors, symptoms and signs and different types of management of the disease.

Patients and Methods: A prospective study of 40 patients from the period January 2012 - January 2014, and conducted in Gazi Al-Hariri Hospital of Surgical Specialties, disregarding the age, complaining of chronic subdural hematoma as proved by $\mathrm{CT}$ scan. It includes the predisposing factors, the symptoms and signs, the location of hematoma, mode of treatment, complications and the outcome.

Results: In this study the highest incidence of CSDH was above 50 year and the second age group was below 1 year. It was more common in males than females and they were unilateral more than bilateral, as shown by C.T scan which was the most reliable method for diagnosis and assessment.

Conclusions: The most suitable treatment was burr hole in the older age group but craniotomy with membranectomy were still performed. In patients below 1 year, subdural peritoneal shunt found to be the method of choice. This study shows that the most common complications are the recurrence and infection. Outcome depends mainly on the early recognition and treatment.

Keywords: Chronic subdural hematoma, traumatic brain injury, Burr hole aspiration.

\section{Introduction:}

Definition: Chronic subdural hematoma is a blood collection in the subdural space for more than 3 weeks from the onset of the bleeding. (1) It is more likely to develop in infancy and after the age of 60 years. A high incidence in the former probably related to birth injury and bleeding tendency in infancy. In old age group, brain atrophy renders the bridging veins as they traverse the subdural space more vulnerable to injury. Young adults with chronic SDH should arouse suspicion of some element of brain atrophy. (1) Incidence: The incidence of Chronic SDH is $1-2$ per 100,000 people per year. The majority of patients are over 60 years or older, $25-50 \%$ of patients have history of head trauma. (2) Anatomy: Subdural space is a potential space between the dura matter and the arachnoid matter. It contains a thin film of serous fluid. It doesn't appear to communicate with the subarachnoid space. The subdural space extends separately into the interhemispheric fissure along with both sides of the falx, because of the firm attachment of the thin inferior sagittal sinus. (3) The thin walled veins of the central nervous system cross the subdural space and are likely to be torn by a sudden movement of the brain leading to slow venous leakage of blood into the subdural space. (4)

*Dept. of surgery, college of medicine, University of Baghdad.

Email: ali_alshalchy@yahoo.com

**Ghazi Al-Hariri hospital.
Stages of Subdural Hematoma: There are four recognized anatomic stages which could supply the basis for an estimate of the time from the onset of the hemorrhage: -For the first 18 hours, the subdural blood remains fluid or formed soft with non-adherent clots. During the 2nd and 3rddays, the clots are recognizably firmer and adherent to the dura. -From the 4thday through the 2ndweek, the blood is very dark, clotted and sometimes separates to form yellow fluid. Evidence of organization is visible on the dural surface, but there's no inner membrane or neomembrane. The last stage consists of the formation of the neomembrane which was observed in the patients after 39 days from the injury. (5) Etiology: Trauma: Which is the most common cause in spite of the fact that preceding trauma is usually trivial, as sometimes unnoticed, $20-30 \%$ of the patients fail to give history of injury. $(2,5,6)$-Post Shunt: After the treatment of hydrocephalous with ventricular shunt especially in children. There is a chance for the development of a chronic subdural hematoma due to the siphon effect of shunt and the delayed expansion of brain which leads to rupture of the bridging veins which cross the subdural space. Once this complication occurs it's difficult to treat because we have either to choose between draining the blood and closing the shunt. (6) -Coagulopathy: such as hemophilia or leukemia. Such hematomas probably are not truly spontaneous; however, they are associated with other sign of bleeding tendency or history of 
trauma. (2) -Alcoholism: which may precipitate brain atrophy and impairs of the functions of the liver. (7)

-Liver cirrhosis: associated with vitamin $\mathrm{k}$ deficiency or clotting defect. (6) -Preexisting brain pathology: such as arachnoid cyst which may be associated with failure of development of temporal lobe that may precipitate a chronic subdural hematoma. (8) Arteriovenous malformation (AVM): such as dural AVM, this may rarely precipitate chronic SDH. (9)

-Rupture of saccular or mycotic aneurysm: such as aneurysm of the peripheral branches of the middle cerebral artery. (6) -Chronic sub dural hematoma might follow lumber spinal cerebrospinal fluid drainage after a lumber puncture. (9) -Metastatic infiltration of dura matter. (7)

\section{Patients and Methods:}

A prospective study of 40 patients of different age populations from January 2012 to January 2014 includes all patients of chronic subdural hematoma admitted to the Gazi Al-Hariri hospital in Medical Teaching Complex in Baghdad. During this study the considerations that were taken included:

-The presentation of patients.

-Investigations which included: brain CT scan which was the most reliable diagnostic tool, as all of the patients were diagnosed by CT scan.

-The type of treatment which included burr hole, craniotomy with membranectomy, subdural peritoneal shunt.

-The outcome.

-The complications.

Those patients who complained from minimum symptoms and signs were treated by conservative measures which included bed rest and corticosteroids. Those patients who did not need surgery were included in the study. Check scan were performed at two weeks interval to assess the progress of the condition. Those patients who needed surgery, their treatment and the type of anesthesia were dictated by their general condition. The old and unfit patients were operated under local anesthesia and burr hole drainage was performed. Those who were fit and in a good general condition, operations were done under general anesthesia, and the operation ranged from simple burr hole drainage to an extensive craniotomy. Children and those below 1 year of age were treated mainly with subdural-peritoneal shunt. All the patients submitted to operation, were put on prophylactic antibiotics. The location of the burr hole was determined by the site of the hematoma as determined by the preoperative CT scan. Mostly two burr holes were done in the frontal and the parietal region unless otherwise indicated. For bilateral hematoma both side were drained. For subdural-peritoneal shunt, only the lower end of the shunt system was used (Zero shunting). Finally, the study shows the condition of the postoperative follow-up for 1 month.

\section{Results:}

Table: 1 Age distribution of 40 patients with chronic SDH.

\begin{tabular}{lll}
\hline \multicolumn{1}{r}{ Age (years) } & No. of patients & Incidence \\
\hline$\leq 1$ & 10 & $25 \%$ \\
\hline $1-10$ & 6 & $15 \%$ \\
\hline $10-20$ & 1 & $2.5 \%$ \\
\hline $20-30$ & 0 & - \\
\hline $30-40$ & 1 & $2.5 \%$ \\
\hline $40-50$ & 2 & $5 \%$ \\
\hline$\geq 50$ & 20 & $50 \%$ \\
\hline Total & 40 & $100 \%$ \\
\hline
\end{tabular}

Table: 2 Gender distributions of 40 patients with Chronic SDH.

\begin{tabular}{lll}
\hline \multicolumn{1}{c}{ Gender } & No. of patients & Incidence \\
\hline Male & 33 & $82.5 \%$ \\
\hline Female & 7 & $17.5 \%$ \\
\hline Total & 40 & $100 \%$ \\
\hline
\end{tabular}

Table: 3 Etiology of chronic SDH.

\begin{tabular}{lll}
\hline Etiology & No. of patients & Incidence \\
\hline Trauma & 22 & $55 \%$ \\
\hline Post shunting & 6 & $15 \%$ \\
\hline Liver cirrhosis & 2 & $5 \%$ \\
\hline Bleeding tendency & 1 & $2.5 \%$ \\
\hline Unknown & 9 & $22.5 \%$ \\
\hline Total & 40 & $100 \%$ \\
\hline
\end{tabular}

Table: 4 Pediatric patients' distribution according to etiology.

\begin{tabular}{rrr}
\hline $\begin{array}{r}\text { Pediatric } \\
\text { patients }\end{array}$ & No. of patients & Incidence \\
\hline Post traumatic & 12 & $75 \%$ \\
\hline Post shunting & 4 & $25 \%$ \\
\hline Total & 16 & $100 \%$ \\
\hline
\end{tabular}




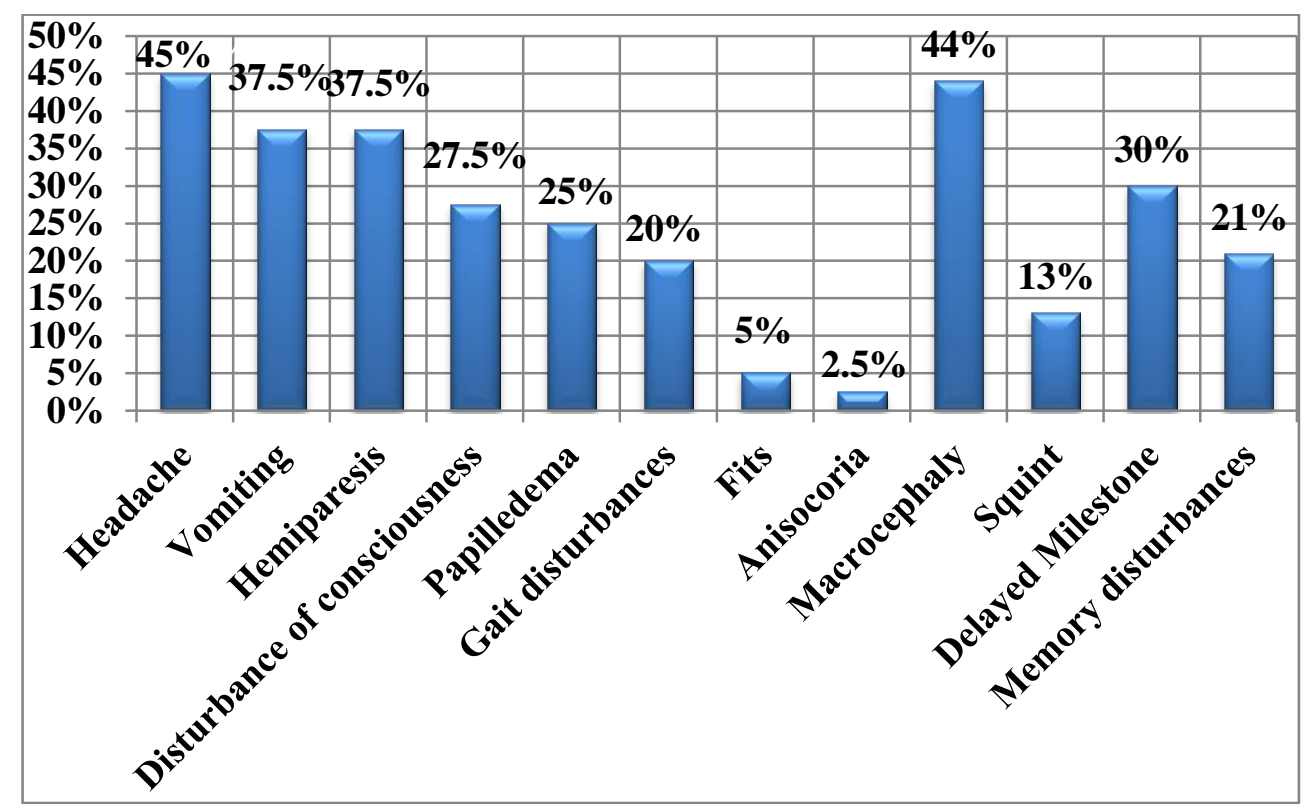

Figure .1 Clinical features of chronic SDH.

Table: 5 the site of collection of chronic SDH as shown by brain CT scan.

\begin{tabular}{lll}
\hline Site of collection & No. of patients & Incidence \\
\hline Bilateral & 5 & $12.5 \%$ \\
\hline Unilateral & 35 & $87.5 \%$ \\
\hline Total & 40 & $100 \%$ \\
\hline
\end{tabular}

Table: 6 the side of collection of chronic SDH as shown by brain CT scan.

\begin{tabular}{lll}
\hline Side of collection & No. of patients & Incidence \\
\hline Left & 19 & $54.3 \%$ \\
\hline Right & 16 & $45.7 \%$ \\
\hline Total & 35 & $100 \%$ \\
\hline
\end{tabular}

Table 7: Management options.

\begin{tabular}{lll}
\hline Management & No. of patients & Incidence \\
\hline Burr hole & 24 & $60 \%$ \\
\hline Craniotomy & 5 & $12.5 \%$ \\
\hline Conservative & 4 & $10 \%$ \\
\hline $\begin{array}{l}\text { Subdural peritoneal } \\
\text { shunt }\end{array}$ & 7 & $17.5 \%$ \\
\hline Total & 40 & $100 \%$ \\
\hline
\end{tabular}

Table8: Outcomes of 40 patients with chronic SDH.

\begin{tabular}{lll}
\hline \multicolumn{1}{c}{ Outcome } & No. of patients & Incidence \\
\hline $\begin{array}{l}\text { Completely } \\
\text { recovered }\end{array}$ & 32 & $80 \%$ \\
\hline Partially recovered & 5 & $12.5 \%$ \\
\hline Dead & 3 & $7.5 \%$ \\
\hline Total & 40 & $100 \%$ \\
\hline
\end{tabular}

Table 9: Complications of chronic SDH.

\begin{tabular}{lll}
\hline Complication & No. of patients & Incidence \\
\hline Postoperative fits & 1 & $2.5 \%$ \\
\hline Recurrence & 2 & $5 \%$ \\
\hline Subdural empyema & 1 & $2.5 \%$ \\
\hline Total & 4 & $10 \%$ \\
\hline
\end{tabular}

Table: 10 Incidence of recurrence per every mode of operation.

\begin{tabular}{|c|c|c|c|}
\hline $\begin{array}{l}\text { Type of } \\
\text { operation }\end{array}$ & $\begin{array}{l}\text { No. of } \\
\text { patients } \\
\text { managed by } \\
\text { that type of } \\
\text { operation }\end{array}$ & $\begin{array}{l}\text { No. of } \\
\text { patients with } \\
\text { recurrence }\end{array}$ & Incidence \\
\hline Burr hole & 24 & 2 & $8.33 \%$ \\
\hline Craniotomy & 5 & Zero & Zero \\
\hline $\begin{array}{l}\text { Subdural } \\
\text { Peritoneal } \\
\text { shunt }\end{array}$ & 7 & Zero & Zero \\
\hline Total & 36 & 2 & $8.33 \%$ \\
\hline
\end{tabular}

Table: 11 Incidence of recurrence in patients treated with burr whole surgery alone versus burr hole with steroid.

\begin{tabular}{lllll}
\hline $\begin{array}{l}\text { Type } \\
\text { operation }\end{array}$ & $\begin{array}{l}\text { No. } \\
\text { patients }\end{array}$ & of & Recurrence & Incidence \\
\hline $\begin{array}{l}\text { Burr hole } \\
\text { alone }\end{array}$ & 16 & 2 & $12.5 \%$ \\
\hline $\begin{array}{l}\text { Burr hole } \\
\text { with steroid }\end{array}$ & 8 & Zero & Zero \\
\hline Total & 24 & 2 & $12.5 \%$ \\
\hline
\end{tabular}

\section{Discussion:}

According to our study the majority of the patients were over the age of 50 and represent about $50 \%$ of the total number. This high percent may be related to the higher sensitivity of this group to trauma as their visual and ability deteriorate. Brain atrophy which is more severe in the older age group renders even minor trauma enough to produce chronic subdural hematoma, as stated by Lucas B. et al. (10) The second common age group is below 1 year of age and this may be attributed to their vulnerability to trauma and to the higher incidence of hydrocephalus which necessitates a ventricular shunt and this may result in increase the 
chance of post shunting chronic subdural hematomas as a complication and this finding is similar to the result found by Young J. et al. (11) Males were more affected than females and this may be due to the residence of the old age females at home in our country. In this study trauma comprises $55 \%$ and this is comparative with the study done by Khalid K. et al. They found that (1/4) of their patients where with unknown etiology which is nearly similar to our figure $(22.5 \%)$. Those patients with unknown etiology might result from minor trauma that might be forgotten by the patient. (12) The post shunting chronic subdural hematoma might develop in the infant being the largest group affected; this might be related to fact of rapid decompression of ventricle by the shunt device or spillage of C.S.F during brain cannulation. This found also by George L.K. (13) Infant with hydrocephalous develops considerable increase in skull size in which case brain substance decrease with huge expansion of infant skull. With implantation of shunt big craniocerebral disproportion develop which will invite to development of chronic subdural hematoma, which is the same that had been found by Yang W. et al. (6) Headache was the most common presenting symptom followed by vomiting and hemiparesis and this nearly similar to the result of study of Ramnarayan R. et al. (2) Fits occur in (5\%) of the patients and this may be occurred as a result of original trauma and made more severe by the additional effect of the hematoma on the cortex underlying it, this may explain the partial improvement of the patient regarding seizure after evacuation of hematoma. Nearly the same result has been noticed by Costa J. et al. (14) The high percentage of burr holes aspiration was due to its simplicity and can be done under local anesthesia for those patients who cannot tolerate major operation such as craniotomy and membranectomy. Subdural peritoneal shunt comprised $17.5 \%$ from the total surgical procedure, done mostly in children and those below 1 year of age. As seen by Andrew F. et al. (15) The good outcome of conservative treatment may be attributed to the fact that it's applied to patients with very good general condition. This has also been mentioned by Raj K. et al. (9) In this study $80 \%$ of patients completely recovered while only $7.5 \%$ died. The improvement occurred in many symptoms, a part from fit and deterioration in memory, which may be due to the fact that the cognitive abilities of the brain need long time to recover. Death occurred in $7.5 \%$ and this is similar to the figure of the study done by Travis M. et al., those patients who died they were in low score of consciousness and the brain might be damaged severely, that's why they gain no benefit. (16)

\section{Conclusions:}

Major etiology of chronic subdural hematoma is head trauma. -The least possible etiology of chronic subdural hematoma is bleeding tendency. -The major presentation features of chronic subdural hematoma are headache, vomiting and hemiparesis, and to a lesser extent, disturbed level of consciousness Chronic subdural hematoma is managed according to age. In adult age group, the management was mainly by burr hole aspiration, and in children by shunting.

-It is found that burr hole aspiration surgery was superior to craniotomy due to favorable outcome. -In children and those below 1 year of age, shunting procedures were found to be sufficient in the majority of the patients. -The least possibility of recurrence has been reported in patients that are managed by burr hole aspiration and steroids.

Authors' Contributions:

Ali K. AL-Shalchy first supervisor

Wameedh Q. Abdul-Hussein second supervisor

Saif Saad student

\section{References:}

1- Philip J.S., Marcel A.K., Steiger H.S.: Cerebral Perfusion Changes in Chronic Subdural Hematoma. Journal of Neurotrauma, 2013: 347-351.

2- Ramnarayan R., Thimmappa H.: Chronic subdural hematomas-causes of morbidity and mortality. Journal of Surgical Neurology. Vol.67, issue 4, 2007: 367-372.

3-Yasargil M.G.: Anatomy of the cerebral subdural space. Microneurosurgery. Vol.1, 2013: 55-58.

4- Henri D., Françoise C., Risold P.Y.: The Human Hippocampus. Anatomy, 2013: 39-68.

5- Jong W.Y., Hyun P., Sung P.I.: A Study of the Progression from Acute Subdural Hematoma to Chronic Stage Requiring Surgical Treatment. Korean Journal of Neurotrauma.Vol. 9. Issue 2, 2013: 74-80.

6- Yang W.S., Kyung-Soo M.: Recent Changes in Risk Factors of Chronic Subdural Hematoma. Korean Journal of Neurotrauma. Vol.52, issue 3, 2012: 234239.

7- Latini M.F., Fiore C.A., Romano L.M.: Minimally invasive treatment of chronic subdural hematoma in adults. Results in 116 patients.Neurología (English Edition).Vol. 27, Issue 1, 2012: 22-27.

8-Westermaier T., Tilmann S., Ralf-Ingo E.: Arachnoid Cysts. Neurodegenerative Diseases.Advances in Experimental Medicine and Biology. Vol. 724, 2012: 37-50.

9- Raj K., Mahapatra A.K.: Chronic Subdural Hematoma. A Textbook of Head Injury, 2012: 198202.

10- Lucas B., Ernest B.: Chronic subdural hematoma in the elderly: not a benign disease. A Clinical article.Journal of Neurosurgery. Vol. 114, Issue 1, 2011: 72-76. 
11- Young J., Koang-Hum B.: Chronic Subdural Hematoma in Young Adult: An Age Comparison Study. Korean Journal of Neurotrauma. Vol. 9, Issue 1, 2013: 6-11.

12- Khalid K., Mumtaz A.: Management of Chronic Subdural Hematoma. Journal of Postgraduate Medical Institute. Vol. 18, Issue 4, 2011: 651-657.

13- George L.K.: Macrocrania. Symptoms and Signs in Pediatric Surgery, 2012: 27-47.

14- Costa J., Ratilal B.O., Pappamikail A.: Anticonvulsants for preventing seizures in patients withchronic subdural hematoma (Review). The Cochrane collaboration. 2013.

15- Andrew F., Brad E.Z., Peter L.D.: The surgical management of chronic subdural hematoma. Journal of Neurosurgical Review. Vol. 35, Issue 2, 2102: 155169.

16- Travis M.D., Tara G., Bruce I.T.: Chronic Subdural Hematoma: A Sentinel Health Event. Journal of World Neurosurgery. Vol. 80, Issue 6, 2013: 889892. 